\title{
Ectoparasitos de cães e gatos da cidade de Manaus, Amazonas, Brasil
}

\author{
Marcelo Cutrim Moreira de CASTRO ${ }^{1} \&$ José Albertino RAFAEL ${ }^{2}$ \\ RESUMO
}

São apresentados resultados da coleta de ectoparasitos em cães e gatos entre agosto de 2001 e maio de 2002 em diferentes bairros da cidade Manaus. No cão foram encontrados: Ctenocephalidesf. felis (Bouché, 1835) (Siphonaptera, Pulicidae), Heterodoxus spiniger (Enderlein, 1909) (Phthiraptera, Boopidae), Trichodectes canis (De Geer, 1778) (Phthiraptera, Trichodectidae) e Rhipicephalus sanguineus (Latreille,1806) (Acari, Ixodidae). No gato foi coletado C. f. felis. A prevalência de ectoparasitos foi de 80,8\% para cães e $72,7 \%$ para gatos. Para a pulga $C$. f. felis foi de $28,7 \%$ para cães e $72,7 \%$ para gatos. Para o piolho $H$. spiniger foi de $12,3 \%$ para cães. Para o piolho $T$. canis foi de $0,1 \%$ para cães e para o carrapato $R$. sanguineus foi de $63 \%$ para cães. A média de infestação de pulga foi de 1,26 para cães e 1,27 para gatos. A proporção sexual fêmea/macho foi de 1,96:1 no cão e de 3,66:1 no gato. A pulga C. canis (Curtis, 1826), registrada em 1922, não foi coletada.

PALAVRAS-CHAVE

Ectoparasitos, Entomologia Urbana, Phthiraptera, Siphonaptera, Amazonas.

\section{Ectoparasites on cats and dogs from Manaus, Amazonas State, Brazil}

\begin{abstract}
Ectoparasites from different neighborhood of Manaus were collected from august 2001 to May 2002. On dogs it was found: Ctenocephalides f. felis (Bouché, 1835) (Siphonaptera, Pulicidae), Heterodoxus spiniger (Enderlein, 1909) (Phthiraptera, Boopidae), Trichodetes canis (De Geer, 1778) (Phthiraptera, Trichodectidae) and Rhipicephalus sanguineus (Latreille, 1806) (Acari, Ixodidae). On cats: C. f. felis. The prevalence of ectoparasites was $80.8 \%$ to dogs and $72.7 \%$ to cats. For the flea C. f. felis was $28.7 \%$ to dogs and $72.7 \%$ to cats. For the lice $\mathrm{H}$. spiniger was $12.3 \%$ for dogs. For the lice $\mathrm{T}$. canis was $0.1 \%$ for dogs and for the tick R. sanguineus was $63 \%$ for dogs. The infestation index for fleas was 1.26 to dogs and 1.27 to cats. The sexual ratio obtained was 1.96:1 to dogs and 3.66:1 to cats. The flea C. canis (Curtis, 1826) registered in 1922 was not found.
\end{abstract}

\section{KEY WORDS}

Ectoparasites, Urban Entomology, Phthiraptera, Siphonaptera, Amazonas.

\footnotetext{
${ }^{1}$ Mestrando (INPA/CPEN), Av. André Araújo 2936, Petrópolis, CXP. 478, 69011-970, Manaus, Amazonas. E-mail: marcelocutrim@yahoo.com.br ${ }_{2}^{2}$ Pesquisador - Instituto Nacional de Pesquisas da Amazônia (INPA/CPEN). E-mail: jarafael@inpa.gov.br
} 


\section{INTRODUÇÃO}

Os ectoparasitos de animais urbanos são de interesse médicoveterinário pela ação espoliadora e transmissão de agentes patogênicos para seus hospedeiros e à população humana. Em Manaus o conhecimento dessa fauna para cães e gatos está restrito a um estudo feito há mais de oitenta anos por Gordon \& Young (1922). De lá para cá, tanto a população humana quanto a de cães e gatos cresceram muito e desordenadamente, principalmente nos últimos anos. A população humana é de aproximadamente 1.300 .000 e a de cães cerca de 19 mil, sendo 12 mil errantes (inf. pess. Sub-Secretário Municipal de Saúde de Manaus, em 23/04/2002). A população de gatos não tem estimativa. Para manter a população desses animais em níveis aceitáveis a prefeitura mantém um serviço rotineiro de captura dos animais errantes, conhecido popularmente como "carrocinha". Este trabalho teve como objetivo acrescentar e atualizar informaçôes sobre ectoparasitos de cães e gatos errantes e domiciliares de Manaus.

\section{MATERIAL E MÉTODOS}

Os cães e gatos foram examinados vivos entre agosto/2001 e maio/2002 em diferentes bairros da cidade de Manaus. Os cães errantes foram capturados pelo Serviço de Vigilância Sanitária da prefeitura e os domiciliares, assim como os gatos, foram examinados nas residências em visitas a diferentes domicílios. Os cães foram imobilizados com coleiras, tipo enforcador, e os gatos foram manipulados com auxílio de seus donos.

Os ectoparasitos foram coletados manualmente com auxílio de pentes finos e pinças, fazendo vistoria direta no pêlo dos animais. Foram imobilizados com acetato de etila ou álcool $70 \%$ e acondicionados em microtubos contendo álcool $70 \%$. Cada frasco foi etiquetado com um número correspondente ao registro do hospedeiro, anotado em fichas.

No laboratório cada amostra foi colocada em uma placa de Petri com álcool $70 \%$ e analisada sob microscópio estereoscópico (lupa) para identificação, contagem e sexagem. Para a identificação, quando necessário, os espécimes foram diafanizados em ácido láctico $85 \%$, a quente, desidratados em série alcoólica e montados entre lâmina e lamínula com bálsamo do Canadá diluído com xilol. Para a identificaçãao, as seguintes referências foram utilizadas: Aragão \& Fonseca (1961) e Guimarães et al. (2001) para carrapatos; Werneck $(1936,1948)$ para piolhos; Linardi \& Guimarães (2000) e Guimarães et al. (2001) para pulgas. O material testemunho está depositado na coleção de invertebrados do INPA.

\section{RESULTADOS E DISCUSSÃO}

Apresentamos inicialmente os resultados obtidos em 1922 quando foram examinados, em Manaus, os ectoparasitos de cães e gatos (Gordon \& Young, 1922). Naquele ano o método utilizado foi o de sacrificar os cães e gatos com fumaça de enxofre para em seguida coletar manualmente os ectoparasitos, os quais também morriam. Coletaram 4 carrapatos, 18 piolhos e 20 pulgas em 50 cães e 9 gatos. 18 cães e 4 gatos estavam infestados por ectoparasitos. O índice de infestação de ectoparasitos foi de 0,70 em cães e 0,77 em gatos. Os índices para cada espécie estão discriminados na Tabela I. A proporção sexual não foi fornecida. A prevalência total de ectoparasitos foi de $36 \%$ para cães e $44,4 \%$ para gatos e a prevalência para as diferentes espécies está na Tabela I.

Em 2002 foram examinados 73 cães e 11 gatos, todos vivos. 59 cães e 8 gatos estavam infestados por ectoparasitos. As espécies, a quantidade e respectivas proporções sexuais de ectoparasitos registrados estão listadas na Tabela II. O índice de infestação de ectoparasitos foi de 5,27 em cães e 1,27 em gatos. Os índices para cada espécie estão discriminados na Tabela I. A prevalência total de ectoparasitos foi de $80,8 \%$ para cães e $72,7 \%$ para gatos e a prevalência para as diferentes espécies está na Tabela I.

As fêmeas dos ectoparasitos foram registradas em maior número para todas as espécies. Os números absolutos para cada espécie/sexo são apresentados na Tabela II.

A pulga C. canis, registrada em 1922, não foi coletada em 2001-2002.

Tabela 1 - Prevalência (\%), números absolutos de hospedeiros infestados (entre parênteses) e intensidade de infestação (entre colchetes) de ectoparasitos obtidos em Manaus em 1922 e em 2001-2002.

\begin{tabular}{|c|c|c|c|c|c|c|}
\hline \multirow{2}{*}{$\begin{array}{c}1922 \\
\text { Hospedeiro }\end{array}$} & \multicolumn{6}{|c|}{ Ectoparasitos } \\
\hline & Ctenocephalides canis & Ctenocephalides $f$. felis & Trichodectes canis ${ }^{\star \star}$ & Heterodoxus spiniger* & Ripicephalus sanguineus & Total \\
\hline Cão n=50 & $22 \%(11)[0,26]$ & & $6 \%(3)[0,32]$ & $4 \%(2)[0,04]$ & $4 \%(2)[0,08]$ & $36 \%(18)[0,70]$ \\
\hline Gato $n=9$ & $44,4 \%(4)[0,77]$ & & & & & $44,4 \%$ (4) $[0,77]$ \\
\hline 2001-2002 & \multicolumn{6}{|c|}{ Ectoparasitos } \\
\hline Hospedeiro & Ctenocephalides canis & Ctenocephalides $f$. felis & Trichodectes canis ${ }^{\star \star}$ & Heterodoxus spiniger* & Ripicephalus sanguineus & Total \\
\hline Cão $n=73$ & & $38,3 \%(28)[1,26]$ & $1,36 \%(1)[0,01]$ & $13,6 \%(10)[0,82]$ & $63 \%(46)[3,08]$ & $80,8 \%(59)[5,17]$ \\
\hline Gato $n=11$ & & $72,7 \%$ (8) $[1,27]$ & & & & $72,7 \%$ (8) $[1,27]$ \\
\hline
\end{tabular}


Tabela 2 - Número de ectoparasitos, machos e fêmeas, em cães e gatos na cidade de Manaus em 2001-2002.

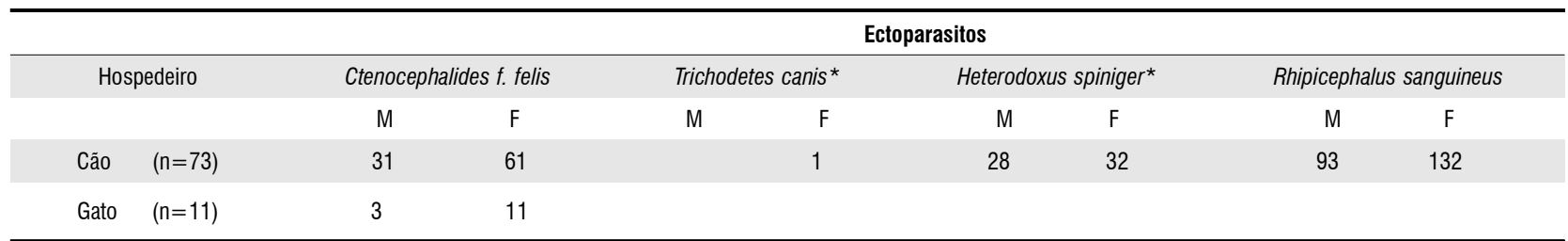

(n) = número de indivíduos examinados; $\mathrm{M}=$ macho; $\mathrm{F}=$ fêmea

* Espécie tratada como Heterodoxus longitarsus por Gordon \& Young (1922)

** Espécie tratada como Trichodectes latus por Gordon \& Young (1922)

Apesar da diferença na metodologia entre os dois trabalhos é possível fazer algumas comparaçōes, isso porque os trabalhos com ectoparasitos utilizam o animal como unidade de coleta. Aqui comparamos os resultados tomando por base o número de cães e gatos coletados nas duas épocas. $\mathrm{O}$ mesmo procedimento é feito quando as comparações são feitas com os trabalhos mais recentes e citados abaixo.

Na comparação dos resultados obtidos em 1922 e os obtidos em 2001-2002 é observado que as espécies de ectoparasitos são as mesmas, exceto pela substituição de uma espécie de pulga. Naquela época Gordon \& Young (1922) registraram Ctenocephalides canis (Curtis, 1826) enquanto em 2001-2002 registramos Ctenocephalidesf. felis (Bouché, 1835). Atualmente a espécie que predomina nos cães e gatos em Manaus é $C$. felis felis, espécie de clima tropical, resultado que concorda com os obtidos para Belo Horizonte (Linardi \& Nagem, 1973), para o estado de Minas Gerais (Raszl et al., 1999), para Goiânia (Lustosa, 1973), para Vitória (Costa et al., 1990) e Rio de Janeiro (Fernandes et al., 1996). Discorda para o estado de Roraima onde a pulga registrada foi C. canis (Santiago \& Costa, 1974). Não há material testemunho dos espécimes de Roraima para verificar a identificação específica.

O resultado de Manaus indica duas possibilidades: 1) que ocorreu o desaparecimento de $C$. canis ou 2) que seu índice populacional é muito baixo e não foi detectada neste estudo. $C$. canis é mais comum em áreas temperadas e mais rara em áreas tropicais (Hopkins \& Rothschild, 1953). A explicação para a predominância de C. canis em 1922, se a identificação foi feita corretamente (não há informação de depósito de espécimes testemunhos em coleções científicas para confirmar a identificação), é que Manaus esteve sob grande influência da colonização européia no final do século retrasado e início do século passado; os imigrantes trouxeram seus animais domésticos infestados pela pulga predominante na Europa, C. canis, e a mesma predominava entre os animais locais. Com o tempo, esta espécie foi sendo substituída por $C$. f. felis, espécie adaptada ao clima tropical e que hoje predomina na cidade de Manaus.

O índice de infestação das espécies registradas de ectoparasitos aumentou nos cães de 0,70 para 5,17 e nos gatos de 0,77 para
1,27. O índice de infestação de pulgas aumentou nos cachorros de 0,26 para 1,26 e nos gatos de 0,77 para 1,27 . A prevalência de ectoparasitos aumentou de $36 \%$ para $80,8 \%$ em cães e de $44,4 \%$ para $72,7 \%$ em gatos.

$\mathrm{O}$ aumento da densidade populacional de ectoparasitos em cães e gatos na cidade de Manaus se deve ao aumento da população humana e conseqüentemente da população de cachorros e gatos em condições favoráveis (clima e alimento abundante) para os mesmos.

Considerando os valores obtidos para as pulgas podemos verificar que o índice de infestação em Manaus $(1,27)$ pode ser considerado baixo quando comparado com 1,40 em Salvador (Menezes, 1954); 11,7 em Curitiba (Artigas \& Unti, 1934) e 15,9 em Belo Horizonte (Linardi \& Nagem, 1973).

A prevalência de pulga é muito variável em diferentes regiōes brasileiras e os valores obtidos em Manaus, 38,3\% para cães e $72,7 \%$ para gatos, estão dentro das variações obtidas para outras regiōes. Em Curitiba 63,3\% para cães (Artigas \& Unti, 1934); em Uberlândia 28,02\% para cães e $66,67 \%$ para gatos (Raszl et al., 1999); em Belo Horizonte 87,23\% para cães (Linardi \& Nagem, 1973) e no Rio de Janeiro 50,9\% para cães e 68,8\% para gatos (Fernandes et al., 1996).

\section{CONCLUSÃO}

Apesar da metodologia utilizada em 1922 não ser a mesma nas coletas de 2001-2002, este trabalho atualiza as informações taxonômicas sobre os ectoparasitos de animais domésticos, cães e gatos, da cidade de Manaus. Foi possível verificar que a fauna atual de ectoparasitos é semelhante à registrada em 1922 por Gordon \& Young (1922). A diferença foi a substituição de Ctenocephalides canis por Ctenocephalidesf. felis, a última adaptada ao clima tropical. Verificamos aumento na densidade dos ectoparasitos, mas não foi possível fazer outras comparaçōes porque não há informaçôes sobre o censo populacional de cachorros e gatos em 1922.

\section{AGRADECIMENTOS}

Ao Dr. Pedro Marcos Linardi, UFMG, pela leitura e comentários ao manuscrito e aos dois revisores anônimos que contribuíram com esse artigo. 


\section{BIBLIOGRAFIA CITADA}

Aragão, H; Fonseca, F. 1961. Notas de Ixodologia. VIII. Lista e chave para os representantes da fauna ixodológica brasileira. Mem. Inst. Oswaldo Cruz, 59(2): 115-156.

Artigas, P.; Unti, O. 1934. Sobre a Presença de Ctenocephalides canis (Curtis, 1896), em Curitiba. Bol. Biol., 2(2): 34-38.

Costa, J.O.; Guimarães, M.P.; Lima, W.S. 1990. Freqüência de endo e ectoparasitos de cães capturados nas ruas de Vitória ES, Brasil. Arq. Bras. Méd. Vet. Zoot., 42(5): 451-452.

Fernandes, C.G.; Linardi, P.M.; Faccini, J.L.H.; Moura, S.T. 1996. Pulicídeos de cães e gatos da cidade do Rio de Janeiro (RJ, Brasil) e municípios vizinhos. Rev. Univ. Rural, Sér. Ciênc. Vida, 18(1-2): 115-118.

Guimarães, J.H; Tucci, E.C; Barros-Battesti, D.M. 2001. Ectoparasitos de Importância Veterinária. Ed. Plêiade/FAPESP,SP. 218pp.

Gordon, R.M; Young, C.J. 1922. Parasites in dogs and cats in Amazonas. Ann. Trop. Med. Parasitol., 16(3): 297-300.

Hopkins G.H.E.; Rothschild, M. 1953. An illustrated catalogue of the Rothschild collection offleas (Siphonaptera) in the British Museum (Natural History). Vol I, London, British Museum (Natural History). 361pp.

Linardi, P.M; Nagem, R.L; 1973. Pulicídeos e outros ectoparasitos de cães em Belo Horizonte e municípios vizinhos. Rev. brasil. Biol, 33(4): 529-538.
Linardi, P.M; Guimarães, L.R. 2000. Sifonápteros do Brasil. Mus. de Zool., USP/FAPESP. 173pp.

Lustosa, E.S. 1973. Ectoparasitos de cães vadios de Goiânia. Revta. Patol. Trop., 2: 397-399.

Menezes, O.B. 1954. Parasitos de Canis familiaris em Salvador. Bol. Inst. Biol. Bahia, 1(1): 75-78.

Raszl, S.M.; Cabral D.D.; Linardi, P.M. 1999. Notas sobre Sifonápteros (Pulicídae, Tungidae e Rhopalopsyllidae) de carnívoros domésticos brasileiros. Rev. Bras. Ent., 43(1/2): 9597.

Santiago, M.A.M; Costa, U.C. 1974. Ocorrência de parasitos nos animais domésticos do Território de Roraima. Rev. Méd. Vet., 9(3): 95-97

Werneck, F.L. 1936. Contribuições ao conhecimento de Mallophagos encontrados nos mamíferos sul-americanos. Mem. Inst. Oswaldo Cruz, 31(3): 391-589.

Werneck, F.L. 1948. Os Malófagos de Mamiferos. Parte 1: Amblycera e Ischnocera (Philopteridae e parte de Trichodectidae). Edição da Revista Brasileira de Biologia, Rio de Janeiro, Editora: IBGE. 239 pp.

Recebido em 19/08/2005

Aceito em 06/11/2006 